\title{
A new approach to $G$-metric and related fixed point theorems
}

\author{
Mehdi Asadi ${ }^{1}$, Erdal Karapınar ${ }^{2 *}$ and Peyman Salimi ${ }^{3}$
}

${ }^{\text {*Correspondence: }}$ erdalkarapinar@yahoo.com;

ekarapinar@atilim.edu.tr

${ }^{2}$ Atilim University, Incek, Ankara

06836, Turkey

Full list of author information is

available at the end of the article

\begin{abstract}
Very recently, Samet et al. and Jleli and Samet reported that most of fixed point results in the context of G-metric space, defined by Sims and Zead, can be derived from the usual fixed point theorems on the usual metric space. In this paper, we state and prove some fixed point theorems in the framework of $\mathrm{G}$-metric space that cannot be obtained from the existence results in the context of associated metric space.
\end{abstract}

\section{Introduction and preliminaries}

In 2007, Mustafa and Sims introduced the notion of G-metric and investigated the topology of such spaces. The authors also characterized some celebrated fixed point results in the context of $G$-metric space. Following this initial paper, a number of authors have published many fixed point results on the setting of G-metric space (see, e.g., [1-33] and the references therein). Samet et al. [24] and Jleli and Samet [25] reported that some published results can be considered as a straight consequence of the existence theorem in the setting of the usual metric space. More precisely, the authors of these two papers noticed that $p(x, y)=p_{G}(x, y)=G(x, y, y)$ is a quasi-metric whenever $G: X \times X \times X \rightarrow[0, \infty)$ is a $G$-metric. It is evident that each quasi-metric induces a metric. In particular, if the pair $(X, p)$ is a quasi-metric space, then the function defined by

$$
d(x, y)=d_{G}(x, y)=\max \{p(x, y), p(y, x)\}, \quad \text { for all } x, y \in X,
$$

forms a metric on $X$.

The object of this paper is to get some fixed point results in the context of G-metric space that cannot be concluded from the existence results. This paper can be considered as a continuation of [27], which was inspired by [26].

First, we recollect some necessary definitions and results in this direction. The notion of $G$-metric spaces is defined as follows.

Definition 1.1 (See [1]) Let $X$ be a non-empty set, $G: X \times X \times X \rightarrow \mathbb{R}^{+}$be a function satisfying the following properties:

(G1) $G(x, y, z)=0$ if $x=y=z$,

(G2) $0<G(x, x, y)$ for all $x, y \in X$ with $x \neq y$,

(G3) $G(x, x, y) \leq G(x, y, z)$ for all $x, y, z \in X$ with $y \neq z$,

(G4) $G(x, y, z)=G(x, z, y)=G(y, z, x)=\cdots$ (symmetry in all three variables),

(G5) $G(x, y, z) \leq G(x, a, a)+G(a, y, z)$ (rectangle inequality) for all $x, y, z, a \in X$. 
Then function $G$ is called a generalized metric or, more specifically, a $G$-metric on $X$, and the pair $(X, G)$ is called a $G$-metric space.

Note that every $G$-metric on $X$ induces a metric $d_{G}$ on $X$ defined by

$$
d_{G}(x, y)=G(x, y, y)+G(y, x, x), \quad \text { for all } x, y \in X .
$$

For a better understanding of the subject, we give the following examples of $G$-metrics.

Example 1.1 Let $(X, d)$ be a metric space. Function $G: X \times X \times X \rightarrow[0,+\infty)$, defined by

$$
G(x, y, z)=\max \{d(x, y), d(y, z), d(z, x)\},
$$

for all $x, y, z \in X$, is a $G$-metric on $X$.

Example 1.2 (See, e.g., [1]) Let $X=[0, \infty)$. Function $G: X \times X \times X \rightarrow[0,+\infty)$, defined by

$$
G(x, y, z)=|x-y|+|y-z|+|z-x|
$$

for all $x, y, z \in X$, is a $G$-metric on $X$.

In their initial paper, Mustafa and Sims [1] also defined the basic topological concepts in $G$-metric spaces as follows.

Definition 1.2 (See [1]) Let $(X, G)$ be a $G$-metric space, and let $\left\{x_{n}\right\}$ be a sequence of points of $X$. We say that $\left\{x_{n}\right\}$ is $G$-convergent to $x \in X$ if

$$
\lim _{n, m \rightarrow+\infty} G\left(x, x_{n}, x_{m}\right)=0,
$$

that is, for any $\varepsilon>0$, there exists $N \in \mathbb{N}$ such that $G\left(x, x_{n}, x_{m}\right)<\varepsilon$ for all $n, m \geq N$. We call $x$ the limit of the sequence and write $x_{n} \rightarrow x$ or $\lim _{n \rightarrow+\infty} x_{n}=x$.

Proposition 1.1 (See [1]) Let $(X, G)$ be a G-metric space. The following are equivalent:

(1) $\left\{x_{n}\right\}$ is G-convergent to $x$,

(2) $G\left(x_{n}, x_{n}, x\right) \rightarrow 0$ as $n \rightarrow+\infty$,

(3) $G\left(x_{n}, x, x\right) \rightarrow 0$ as $n \rightarrow+\infty$,

(4) $G\left(x_{n}, x_{m}, x\right) \rightarrow 0$ as $n, m \rightarrow+\infty$.

Definition 1.3 (See [1]) Let $(X, G)$ be a $G$-metric space. Sequence $\left\{x_{n}\right\}$ is called a $G$-Cauchy sequence if, for any $\varepsilon>0$, there exists $N \in \mathbb{N}$ such that $G\left(x_{n}, x_{m}, x_{l}\right)<\varepsilon$ for all $m, n, l \geq N$, that is, $G\left(x_{n}, x_{m}, x_{l}\right) \rightarrow 0$ as $n, m, l \rightarrow+\infty$.

Proposition 1.2 (See $[1])$ Let $(X, G)$ be a G-metric space. Then the following are equivalent:

(1) sequence $\left\{x_{n}\right\}$ is G-Cauchy,

(2) for any $\varepsilon>0$, there exists $N \in \mathbb{N}$ such that $G\left(x_{n}, x_{m}, x_{m}\right)<\varepsilon$ for all $m, n \geq N$.

Definition 1.4 (See [1]) A G-metric space $(X, G)$ is called $G$-complete if every $G$-Cauchy sequence is $G$-convergent in $(X, G)$. 
Definition 1.5 Let $(X, G)$ be a $G$-metric space. Mapping $F: X \times X \times X \rightarrow X$ is said to be continuous if for any three $G$-convergent sequences $\left\{x_{n}\right\},\left\{y_{n}\right\}$ and $\left\{z_{n}\right\}$ converging to $x, y$ and $z$, respectively, $\left\{F\left(x_{n}, y_{n}, z_{n}\right)\right\}$ is $G$-convergent to $F(x, y, z)$.

Mustafa [4] extended the well-known Banach [34] contraction principle mapping in the framework of $G$-metric spaces as follows.

Theorem 1.1 (See [4]) Let $(X, G)$ be a complete G-metric space and $T: X \rightarrow X$ be a mapping satisfying the following condition for all $x, y, z \in X$ :

$$
G(T x, T y, T z) \leq k G(x, y, z)
$$

where $k \in[0,1)$. Then $T$ has a unique fixed point.

Theorem 1.2 (See [4]) Let $(X, G)$ be a complete G-metric space and $T: X \rightarrow X$ be a mapping satisfying the following condition for all $x, y \in X$ :

$$
G(T x, T y, T y) \leq k G(x, y, y)
$$

where $k \in[0,1)$. Then $T$ has a unique fixed point.

Remark 1.1 We notice that condition (2) implies condition (3). The converse is true only if $k \in\left[0, \frac{1}{2}\right)$. For details see [4].

Lemma 1.1 [4] By the rectangle inequality (G5) together with the symmetry (G4), we have

$$
G(x, y, y)=G(y, y, x) \leq G(y, x, x)+G(x, y, x)=2 G(y, x, x) .
$$

\section{Main results}

Theorem 2.1 Let $(X, G)$ be a complete G-metric space and $T: X \rightarrow X$ be a mapping satisfying the following condition for all $x, y \in X$ :

$$
G(T x, T y, T y) \leq k G(x, T x, y)
$$

where $k \in[0,1)$. Then $T$ has a unique fixed point.

Proof Let $x_{0} \in X$ be an arbitrary point, and define the sequence $x_{n}$ by $x_{n}=T^{n}\left(x_{0}\right)$. By (5), we have

$$
G\left(x_{n}, x_{n+1}, x_{n+1}\right) \leq k G\left(x_{n-1}, x_{n}, x_{n}\right) .
$$

Continuing in the same argument, we will get

$$
G\left(x_{n}, x_{n+1}, x_{n+1}\right) \leq k^{n} G\left(x_{0}, x_{1}, x_{1}\right) .
$$


Moreover, for all $n, m \in \mathbb{N} ; n<m$, we have by rectangle inequality that

$$
\begin{aligned}
G\left(x_{n}, x_{m}, x_{m}\right) \leq & G\left(x_{n}, x_{n+1}, x_{n+1}\right)+G\left(x_{n+1}, x_{n+2}, x_{n+2}\right) \\
& +G\left(x_{n+2}, x_{n+3}, x_{n+3}\right)+\cdots+G\left(x_{m-1}, x_{m}, x_{m}\right) \\
\leq & \left(k^{n}+k^{n+1}+k^{n+2}+\cdots+k^{m-1}\right) G\left(x_{0}, x_{1}, x_{1}\right) \\
\leq & \frac{k^{n}}{1-k} G\left(x_{0}, x_{1}, x_{1}\right),
\end{aligned}
$$

and so, $\lim G\left(x_{n}, x_{m}, x_{m}\right)=0$, as $n, m \rightarrow \infty$. Thus, $\left\{x_{n}\right\}$ is G-Cauchy sequence. Due to the completeness of $(X, G)$, there exists $u \in X$ such that $\left\{x_{n}\right\}$ is $G$-convergent to $u$.

Suppose that $T u \neq u$, then

$$
G\left(x_{n}, T u, T u\right) \leq k G\left(x_{n-1}, x_{n}, u\right)
$$

taking the limit as $n \rightarrow \infty$, and using the fact that function $G$ is continuous, then

$$
G(u, T u, T u) \leq k G(u, u, u) .
$$

This contradiction implies that $u=T u$.

To prove uniqueness, suppose that $u \neq v$ such that $T v=v$, and use Lemma 1.1, then

$$
G(u, u, v)=G(T u, T u, T v) \leq k G(u, T u, v)=k G(u, u, v)
$$

which implies that $u=v$.

Example 2.1 Let $X=[0, \infty)$ and

$$
G(x, y, z)= \begin{cases}0, & \text { if } x=y=z \\ \max \{x, y, z\}, & \text { otherwise }\end{cases}
$$

be a G-metric on $X$. Define $T: X \rightarrow X$ by $T x=\frac{1}{5} x$. Then the condition of Theorem 2.1 holds. In fact,

$$
G(T x, T y, T y)=\frac{1}{5} \max \{x, y\}
$$

and

$$
G(x, T x, y)=\max \{x, y\}
$$

and so,

$$
G(T x, T y, T y) \leq \frac{1}{4} G(x, T x, y)
$$

That is, conditions of Theorem 2.1 hold for this example. 
Corollary 2.1 Let $(X, G)$ be a complete G-metric space and $T: X \rightarrow X$ be a mapping satisfying the following condition for all $x, y, z \in X$ :

$$
G(T x, T y, T z) \leq a G(x, T x, z)+b G(x, T x, y)
$$

where $0 \leq a+b<1$. Then $T$ has a unique fixed point.

Theorem 2.2 Let $(X, G)$ be a complete G-metric space and $T: X \rightarrow X$ be a mapping satisfying the following condition for all $x, y \in X$, where $a+b+c+d<1$

$$
G\left(T x, T y, T^{2} y\right) \leq a G\left(x, T x, T^{2} x\right)+b G\left(y, T y, T^{2} y\right)+c G(x, T x, T y)+c G\left(y, T y, T^{3} x\right) .
$$

Then $T$ has a unique fixed point.

Proof Take $x_{0} \in X$. We construct sequence $\left\{x_{n}\right\}_{n=0}^{\infty}$ of points in $X$ in the following way:

$$
x_{n+1}=T x_{n} \quad \text { for all } n=0,1,2, \ldots
$$

Notice that if $x_{n^{\prime}}=x_{n^{\prime}+1}$ for some $n^{\prime} \in \mathbb{N}$, then obviously $T$ has a fixed point. Thus, we suppose that

$$
x_{n} \neq x_{n+1}
$$

for all $n \in \mathbb{N}$.

That is, we have

$$
G\left(x_{n}, x_{n+1}, x_{n+2}\right)>0 \text {. }
$$

From (12), with $x=x_{n-1}$ and $y=x_{n}$, we have

$$
\begin{aligned}
G\left(T x_{n-1}, T x_{n}, T^{2} x_{n}\right) \leq & a G\left(x_{n-1}, T x_{n-1}, T^{2} x_{n-1}\right)+b G\left(x_{n}, T x_{n}, T^{2} x_{n}\right) \\
& +c G\left(x_{n-1}, T x_{n-1}, T x_{n}\right)+d G\left(x_{n}, T x_{n}, T^{3} x_{n-1}\right)
\end{aligned}
$$

which implies that

$$
\begin{aligned}
G\left(x_{n}, x_{n+1}, x_{n+2}\right) \leq & a G\left(x_{n-1}, x_{n}, x_{n+1}\right)+b G\left(x_{n}, x_{n+1}, x_{n+2}\right) \\
& +c G\left(x_{n-1}, x_{n}, x_{n+1}\right)+d G\left(x_{n}, x_{n+1}, x_{n+2}\right),
\end{aligned}
$$

and so,

$$
G\left(x_{n}, x_{n+1}, x_{n+2}\right) \leq k G\left(x_{n-1}, x_{n}, x_{n+1}\right),
$$

where $k=\frac{a+c}{1-b-d}<1$. Then

$$
G\left(x_{n}, x_{n+1}, x_{n+2}\right) \leq k^{n} G\left(x_{0}, x_{1}, x_{2}\right)
$$


for all $n \in \mathbb{N}$. Note that from (G3), we know that

$$
G\left(x_{n}, x_{n}, x_{n+1}\right) \leq G\left(x_{n}, x_{n+1}, x_{n+2}\right)
$$

with $x_{n} \neq x_{n+1}$, and by Lemma 1.1, we know that

$$
G\left(x_{n+1}, x_{n+1}, x_{n}\right) \leq 2 G\left(x_{n}, x_{n}, x_{n+1}\right) .
$$

Then by (13), we have

$$
G\left(x_{n+1}, x_{n+1}, x_{n}\right) \leq 2 k^{n} G\left(x_{0}, x_{1}, x_{2}\right) \text {. }
$$

Moreover, for all $n, m \in \mathbb{N} ; n<m$, we have by rectangle inequality that

$$
\begin{aligned}
G\left(x_{m}, x_{m}, x_{n}\right) \leq & G\left(x_{n}, x_{n+1}, x_{n+1}\right)+G\left(x_{n+1}, x_{n+2}, x_{n+2}\right) \\
& +G\left(x_{n+2}, x_{n+3}, x_{n+3}\right)+\cdots+G\left(x_{m-1}, x_{m}, x_{m}\right) \\
\leq & 2\left(k^{n}+k^{n+1}+k^{n+2}+\cdots+k^{m-1}\right) G\left(x_{0}, x_{1}, x_{2}\right) \\
\leq & \frac{2 k^{n}}{1-k} G\left(x_{0}, x_{1}, x_{2}\right),
\end{aligned}
$$

and so, $\lim G\left(x_{n}, x_{m}, x_{m}\right)=0$, as $n, m \rightarrow \infty$. Thus, $\left\{x_{n}\right\}$ is G-Cauchy sequence. Due to the completeness of $(X, G)$, there exists $u \in X$ such that $\left\{x_{n}\right\}$ is $G$-convergent to $z$. From (12), with $x=x_{n}$ and $y=z$, we have

$$
\begin{aligned}
G\left(T x_{n}, T z, T^{2} z\right) \leq & a G\left(x_{n}, T x_{n}, T^{2} x_{n}\right)+b G\left(z, T z, T^{2} z\right) \\
& +c G\left(x_{n}, T x_{n}, T z\right)+d G\left(z, T z, T^{3} x_{n}\right) .
\end{aligned}
$$

Then

$$
G\left(x_{n+1}, T z, T^{2} z\right) \leq a G\left(x_{n}, x_{n+1}, x_{n+2}\right)+b G\left(z, T z, T^{2} z\right)+c G\left(x_{n}, x_{n+1}, T z\right)+d G\left(z, T z, x_{n+3}\right) .
$$

Taking limit as $n \rightarrow \infty$ in the inequality above, we have

$$
G\left(z, T z, T^{2} z\right) \leq \frac{(c+d)}{1-b} G(z, z, T z)
$$

Now, if $T z=T^{2} z$, then $T$ has a fixed point. Hence, we assume that $T z \neq T^{2} z$. Therefore, by (G3), we get

$$
G\left(z, T z, T^{2} z\right) \leq \frac{(c+d)}{1-b} G(z, z, T z) \leq \frac{(c+d)}{1-b} G\left(z, T z, T^{2} z\right)
$$

which implies that $G\left(z, T z, T^{2} z\right)=0$, i.e., $z=T z=T^{2} z$.

At first, we assume that

$$
\Psi_{1}=\{\psi:[0, \infty) \rightarrow[0, \infty) \text { such that } \psi \text { is non-decreasing and continuous }\}
$$


and

$$
\Phi=\{\varphi:[0, \infty) \rightarrow[0, \infty) \text { such that } \varphi \text { is lower semicontinuous }\}
$$

where $\psi(t)=\phi(t)=0$ if and only if $t=0$.

Theorem 2.3 Let $(X, G)$ be a complete $G$-metric space and $T: X \rightarrow X$ be a mapping satisfying the following condition for all $x, y \in X$, where $\psi \in \Psi$ and $\phi \in \Phi$ holds

$$
\psi\left(G\left(T x, T^{2} x, T y\right)\right) \leq \psi(G(x, T x, y))-\phi(G(x, T x, y))
$$

Then T has a unique fixed point.

Proof Take $x_{0} \in X$. We construct sequence $\left\{x_{n}\right\}_{n=0}^{\infty}$ of points in $X$ in the following way:

$$
x_{n+1}=T x_{n} \quad \text { for all } n=0,1,2, \ldots
$$

Notice that if $x_{n^{\prime}}=x_{n^{\prime}+1}$ for some $n^{\prime} \in \mathbb{N}$, then obviously $T$ has a fixed point. Thus, we suppose that

$$
x_{n} \neq x_{n+1}
$$

for all $n \in \mathbb{N}$.

By (G2), we have

$$
G\left(x_{n}, x_{n+1}, x_{n+1}\right)>0 \text {. }
$$

From (15), with $x=x_{n-1}$ and $y=x_{n}$, we have

$$
\psi\left(G\left(T x_{n-1}, T^{2} x_{n-1}, T x_{n}\right)\right) \leq \psi\left(G\left(x_{n-1}, T x_{n-1}, x_{n}\right)\right)-\phi\left(G\left(x_{n-1}, T x_{n-1}, x_{n}\right)\right)
$$

which implies that

$$
\begin{aligned}
\psi\left(G\left(x_{n}, x_{n+1}, x_{n+1}\right)\right) & \leq \psi\left(G\left(x_{n-1}, x_{n}, x_{n}\right)\right)-\phi\left(G\left(x_{n-1}, x_{n}, x_{n}\right)\right) \\
& \leq \psi\left(G\left(x_{n-1}, x_{n}, x_{n}\right)\right)
\end{aligned}
$$

then $G\left(x_{n}, x_{n+1}, x_{n+1}\right) \leq G\left(x_{n-1}, x_{n}, x_{n}\right)$. So sequence $\left\{G\left(x_{n}, x_{n+1}, x_{n+1}\right)\right\}$ is a decreasing sequence in $\mathbb{R}^{+}$, and thus, it is convergent, say $t \in \mathbb{R}^{+}$. We claim that $t=0$. Suppose, to the contrary, that $t>0$. Taking limit as $n \rightarrow \infty$ in (16), we get

$$
\psi(t) \leq \psi(t)-\phi(t)
$$

which implies $\phi(t)=0$. That is, $t=0$, which is a contrary. Hence, $t=0$, i.e.,

$$
\lim _{n \rightarrow \infty} G\left(x_{n}, x_{n+1}, x_{n+1}\right)=0 .
$$


We shall show that $\left\{x_{n}\right\}_{n=0}^{\infty}$ is a G-Cauchy sequence. Suppose, to the contrary, that there exists $\varepsilon>0$, and sequence $x_{n(k)}$ of $x_{n}$ such that

$$
G\left(x_{m(k)}, T x_{m(k)}, x_{n(k)}\right) \geq \varepsilon
$$

with $n(k) \geq m(k)>k$. Further, corresponding to $m(k)$, we can choose $n(k)$ in such a way that it is the smallest integer with $n(k)>m(k)$ satisfying (19). Hence,

$$
G\left(x_{m(k)}, T x_{m(k)}, x_{n(k)-1}\right)<\varepsilon .
$$

By Lemma 1.1 and (G5), we have

$$
\begin{aligned}
\varepsilon & \leq G\left(x_{m(k)}, T x_{m(k)}, x_{n(k)}\right)=G\left(x_{n(k)}, x_{m(k)}, T x_{m(k)}\right) \\
& \leq G\left(x_{n(k)}, x_{n(k)-1}, x_{n(k)-1}\right)+G\left(x_{n(k)-1}, T x_{m(k)}, x_{m(k)}\right) \\
& \leq G\left(x_{m(k)}, T x_{m(k)}, x_{n(k)-1}\right)+2 s_{n(k)-1} \\
& \leq \varepsilon+2 s_{n(k)-1},
\end{aligned}
$$

where $s_{n(k)-1}=G\left(x_{n(k)-1}, x_{n(k)}, x_{n(k)}\right)$. Letting $k \rightarrow \infty$ in (21), we derive that

$$
\lim _{k \rightarrow \infty} G\left(x_{m(k)}, T x_{m(k)}, x_{n(k)}\right)=\varepsilon
$$

Also, by Lemma 1.1 and (G5), we obtain the following inequalities:

$$
\begin{aligned}
G\left(x_{m(k)}, T x_{m(k)}, x_{n(k)}\right) \leq & G\left(x_{m(k)}, x_{m(k)-1}, x_{m(k)-1}\right)+G\left(x_{m(k)-1}, T x_{m(k)}, x_{n(k)}\right) \\
= & G\left(x_{m(k)}, x_{m(k)-1}, x_{m(k)-1}\right)+G\left(x_{n(k)}, x_{m(k)-1}, T x_{m(k)}\right) \\
\leq & G\left(x_{m(k)}, x_{m(k)-1}, x_{m(k)-1}\right)+G\left(x_{n(k)}, x_{n(k)-1}, x_{n(k)-1}\right) \\
& +G\left(x_{n(k)-1}, x_{m(k)-1}, T x_{m(k)}\right) \\
\leq & 2 s_{m(k)-1}+2 s_{n(k)-1}+G\left(x_{n(k)-1}, x_{m(k)-1}, T x_{m(k)}\right)
\end{aligned}
$$

and

$$
\begin{aligned}
G\left(x_{n(k)-1}, x_{m(k)-1}, T x_{m(k)}\right) \leq & G\left(x_{n(k)-1}, x_{n(k)}, x_{n(k)}\right)+G\left(x_{n(k)}, x_{m(k)-1}, T x_{m(k)}\right) \\
= & G\left(x_{n(k)-1}, x_{n(k)}, x_{n(k)}\right)+G\left(x_{m(k)-1}, T x_{m(k)}, x_{n(k)}\right) \\
\leq & G\left(x_{n(k)-1}, x_{n(k)}, x_{n(k)}\right)+G\left(x_{m(k)-1}, x_{m(k)}, x_{m(k)}\right) \\
& +G\left(x_{m(k)}, T x_{m(k)}, x_{n(k)}\right) \\
= & s_{n(k)-1}+s_{m(k)-1}+G\left(x_{m(k)}, T x_{m(k)}, x_{n(k)}\right) .
\end{aligned}
$$

Letting $k \rightarrow \infty$ in (23) and (24) and applying (22), we find that

$$
\lim _{k \rightarrow \infty} G\left(x_{n(k)-1}, x_{m(k)-1}, T x_{m(k)}\right)=\varepsilon .
$$


Again, by Lemma 1.1 and (G5), we have

$$
\begin{aligned}
G\left(x_{n(k)-1}, x_{m(k)-1}, T x_{m(k)}\right) & =G\left(T x_{m(k)}, x_{m(k)-1}, x_{n(k)-1}\right) \\
& =G\left(x_{m(k)+1}, x_{m(k)-1}, x_{n(k)-1}\right) \\
& \leq G\left(x_{m(k)+1}, x_{m(k)}, x_{m(k)}\right)+G\left(x_{m(k)}, x_{m(k)-1}, x_{n(k)-1}\right) \\
& =G\left(x_{m(k)+1}, x_{m(k)}, x_{m(k)}\right)+G\left(x_{m(k)-1}, x_{m(k)}, x_{n(k)-1}\right) \\
& \leq 2 s_{m(k)}+G\left(x_{m(k)-1}, T x_{m(k)-1}, x_{n(k)-1}\right),
\end{aligned}
$$

and

$$
\begin{aligned}
G\left(x_{m(k)-1}, T x_{m(k)-1}, x_{n(k)-1}\right)= & G\left(x_{m(k)-1}, x_{m(k)}, x_{n(k)-1}\right) \\
\leq & G\left(x_{m(k)-1}, x_{m(k)+1}, x_{m(k)+1}\right)+G\left(x_{m(k)+1}, x_{m(k)}, x_{n(k)-1}\right) \\
\leq & G\left(x_{m(k)-1}, x_{m(k)}, x_{m(k)}\right)+G\left(x_{m(k)}, x_{m(k)+1}, x_{m(k)+1}\right) \\
& +G\left(x_{m(k)+1}, x_{m(k)}, x_{n(k)-1}\right) \\
= & s_{m(k)-1}+s_{m(k)}+G\left(x_{m(k)+1}, x_{m(k)}, x_{n(k)-1}\right) \\
= & s_{m(k)-1}+s_{m(k)}+G\left(x_{m(k)}, T x_{m(k)}, x_{n(k)-1}\right) \\
< & s_{m(k)-1}+s_{m(k)}+\varepsilon .
\end{aligned}
$$

Taking limit as $n \rightarrow \infty$ in (26) and (27) and applying (25), we have

$$
\lim _{k \rightarrow \infty} G\left(x_{m(k)-1}, T x_{m(k)-1}, x_{n(k)-1}\right)=\varepsilon
$$

By (15), with $x=x_{m(k)-1}$ and $y=x_{n(k)-1}$, we have

$$
\begin{aligned}
\psi\left(G\left(x_{m(k)}, T x_{m(k)}, x_{n(k)}\right)\right)= & \psi\left(G\left(T x_{m(k)-1}, T^{2} x_{m(k)-1}, T x_{n(k)-1}\right)\right) \\
\leq & \psi\left(G\left(x_{m(k)-1}, T x_{m(k)-1}, x_{n(k)-1}\right)\right) \\
& -\phi\left(G\left(x_{m(k)-1}, T x_{m(k)-1}, x_{n(k)-1}\right)\right) .
\end{aligned}
$$

Taking limit as $k \rightarrow \infty$ in the inequality above and applying, we have

$$
\psi(\varepsilon) \leq \psi(\varepsilon)-\phi(\varepsilon)
$$

which implies $\varepsilon=0$, which is a contradiction. Then

$$
\lim _{m, n \rightarrow \infty} G\left(x_{m}, T x_{m}, x_{n}\right)=\lim _{m, n \rightarrow \infty} G\left(x_{m}, x_{m+1}, x_{n}\right)=0 .
$$

That is, $\left\{x_{n}\right\}_{0}^{\infty}$ is a Cauchy sequence. Since $(X, G)$ is a $G$-complete, then there exist $z \in X$ such that $x_{n} \rightarrow z$ as $n \rightarrow \infty$. From (15), with $x=x_{n}$ and $y=z$, we have

$$
\begin{aligned}
\psi\left(G\left(x_{n+1}, x_{n+2}, T z\right)\right) & =\psi\left(G\left(T x_{n}, T^{2} x_{n}, T z\right)\right) \\
& \leq \psi\left(G\left(x_{n}, T x_{n}, z\right)\right)-\phi\left(G\left(x_{n}, T x_{n}, z\right)\right) \\
& =\psi\left(G\left(x_{n}, x_{n+1}, z\right)\right)-\phi\left(G\left(x_{n}, x_{n+1}, z\right)\right) .
\end{aligned}
$$


Taking limit as $n \rightarrow \infty$, we get

$$
\psi(G(z, z, T z)) \leq \psi(0)-\phi(0)=0 .
$$

Then $G(z, z, T z)=0$, i.e., $z=T z$. To prove uniqueness, suppose that $z \neq u$, such that $T u=u$. Now, by (15), we get

$$
\psi\left(G\left(T z, T^{2} z, T u\right)\right) \leq \psi(G(z, T z, u))-\phi(G(z, T z, u))
$$

which implies that $\phi(G(z, T z, u))=0$, i.e., $z=u$.

If we take $\psi(t)=t$ and $\phi(t)=(1-r) t$ in Theorem 2.3, where $0 \leq r<1$, then we deduce the following corollary.

Corollary 2.2 Let $(X, G)$ be a complete G-metric space and $T: X \rightarrow X$ be a mapping satisfying the following condition for all $x, y \in X$, where $0 \leq r<1$ holds

$$
G\left(T x, T^{2} x, T y\right) \leq r G(x, T x, y) .
$$

Then $T$ has a unique fixed point.

Example 2.2 Let $X=[0, \infty)$ and

$$
G(x, y, z)= \begin{cases}0, & \text { if } x=y=z, \\ \max \{x, y\}+\max \{y, z\}+\max \{x, z\}, & \text { otherwise }\end{cases}
$$

be a $G$-metric on $X$. Define $T: X \rightarrow X$ by $T x=\frac{1}{4} x$. Then all the conditions of Corollary 2.2 (Theorem 2.3) hold. Indeed,

$$
G\left(T x, T^{2} x, T y\right)=\frac{1}{4} x+\frac{1}{4} \max \left\{\frac{1}{4} x, y\right\}+\frac{1}{4} \max \{x, y\}
$$

and

$$
G(x, T x, y)=x+\max \left\{\frac{1}{4} x, y\right\}+\max \{x, y\},
$$

and so,

$$
G\left(T x, T^{2} x, T y\right) \leq \frac{1}{2} G(x, T x, y)
$$

That is, the conditions of Corollary 2.2 (Theorem 2.3) hold for this example.

Corollary 2.3 Let $(X, G)$ be a complete $G$-metric space and $T: X \rightarrow X$ be a mapping satisfying the following condition for all $x, y, z \in X$, where $0 \leq a+b<2$ holds

$$
G\left(T x, T^{2} x, T y\right)+G\left(T x, T^{2} x, T z\right) \leq a G(x, T x, y)+b G(x, T x, z) .
$$

Then $T$ has a unique fixed point. 
Proof By taking $y=z$, we get

$$
G\left(T x, T^{2} x, T y\right) \leq \frac{(a+b)}{2} G(x, T x, y),
$$

where $0 \leq \frac{(a+b)}{2}<1$. That is, conditions of Theorem 2.3 hold, and $T$ has a unique fixed point.

\section{Fixed point results for expansive mappings}

In this section, we establish some fixed point results for expansive mappings.

Theorem 3.1 Let $(X, G)$ be a complete $G$-metric space and $T: X \rightarrow X$ be an onto mapping satisfying the following condition for all $x, y \in X$, where $\alpha>1$ holds

$$
G\left(T x, T^{2} x, T y\right) \geq \alpha G(x, T x, y) .
$$

Then $T$ has a unique fixed point.

Proof Let $x_{0} \in X$, since $T$ is onto, then there exists $x_{1} \in X$ such that $x_{0}=T x_{1}$. By continuing this process, we get $x_{n}=T x_{n+1}$ for all $n \in \mathbb{N} \cup 0$. In case $x_{n_{0}}=x_{n_{0}+1}$, for some $n_{0} \in \mathbb{N} \cup 0$, then it is clear that $x_{n_{0}}$ is a fixed point of $T$. Now, assume that $x_{n} \neq x_{n+1}$ for all $n$. From (30), with $x=x_{n+1}$ and $y=x_{n}$, we have

$$
\begin{aligned}
G\left(x_{n}, x_{n-1}, x_{n-1}\right) & =G\left(T x_{n+1}, T^{2} x_{n+1}, T x_{n}\right) \\
& \geq \alpha G\left(x_{n+1}, T x_{n+1}, x_{n}\right)=\alpha G\left(x_{n+1}, x_{n}, x_{n}\right),
\end{aligned}
$$

which implies that

$$
G\left(x_{n+1}, x_{n}, x_{n}\right) \leq h G\left(x_{n}, x_{n-1}, x_{n-1}\right),
$$

where $h=\frac{1}{\alpha}<1$. Then we have

$$
G\left(x_{n+1}, x_{n}, x_{n}\right) \leq h^{n} G\left(x_{0}, x_{1}, x_{1}\right) .
$$

By Lemma 1.1, we get

$$
G\left(x_{n}, x_{n+1}, x_{n+1}\right) \leq 2 G\left(x_{n+1}, x_{n}, x_{n}\right) \leq 2 h^{n} G\left(x_{0}, x_{1}, x_{1}\right)
$$

Following the lines of the proof of Theorem 2.1, we derive that $\left\{x_{n}\right\}$ is a Cauchy sequence. Since $(X, G)$ is complete, then there exists $z \in X$ such that $x_{n} \rightarrow z$ as $n \rightarrow \infty$. Consequently, since $T$ is onto, then there exists $w \in X$ such that $z=T w$. From (30), with $x=x_{n+1}$ and $y=w$, we have

$$
G\left(x_{n}, x_{n-1}, z\right)=G\left(T x_{n+1}, T^{2} x_{n+1}, T w\right) \geq \alpha G\left(x_{n+1}, T x_{n+1}, w\right)=\alpha G\left(x_{n+1}, x_{n}, w\right) .
$$

Taking limit as $n \rightarrow \infty$ in the inequality above, we get

$$
G(z, z, w)=\lim _{n \rightarrow \infty} G\left(x_{n}, x_{n-1}, z\right)=0 .
$$


That is, $z=w$. Then $z=T w=T z$. To prove uniqueness, suppose that $u \neq v$ such that $T v=v$ and $T u=u$. Now by (30), we get

$$
G(u, u, v)=G\left(T u, T^{2} u, T v\right) \geq \alpha G(u, T u, v) \geq \alpha G(u, u, v)>G(u, u, v),
$$

which is a contradiction. Hence, $u=v$.

Theorem 3.2 Let $(X, G)$ be a complete G-metric space and $T: X \rightarrow X$ be a mapping satisfying the following condition for all $x, y \in X$, where $a>1$

$$
G\left(T x, T y, T^{2} y\right) \geq \alpha G\left(x, T x, T^{2} x\right) .
$$

Then Thas a unique fixed point.

Proof Let $x_{0} \in X$, since $T$ is onto, then there exists $x_{1} \in X$ such that $x_{0}=T x_{1}$. By continuing this process, we get $x_{n}=T x_{n+1}$ for all $n \in \mathbb{N} \cup 0$. In case $x_{n_{0}}=x_{n_{0}+1}$, for some $n_{0} \in \mathbb{N} \cup 0$, then it is clear that $x_{n_{0}}$ is a fixed point of $T$. Now, assume that $x_{n} \neq x_{n+1}$ for all $n$. From (34), with $x=x_{n+1}$ and $y=x_{n}$, we have

$$
G\left(T x_{n+1}, T x_{n}, T^{2} x_{n}\right) \geq \alpha G\left(x_{n+1}, T x_{n+1}, T^{2} x_{n+1}\right),
$$

which implies that

$$
G\left(x_{n}, x_{n-1}, x_{n-2}\right) \geq \alpha G\left(x_{n+1}, x_{n}, x_{n-1}\right),
$$

and so,

$$
G\left(x_{n+1}, x_{n}, x_{n-1}\right) \leq h G\left(x_{n}, x_{n-1}, x_{n-2}\right),
$$

where $h=\frac{1}{\alpha}<1$. By the mimic of the proof of Theorem 2.1, we can show that $\left\{x_{n}\right\}$ is a Cauchy sequence. Since $(X, G)$ is a complete $G$-metric space, then there exists $z \in X$ such that $x_{n} \rightarrow z$ as $n \rightarrow \infty$. Consequently, since $T$ is onto, then there exists $w \in X$ such that $z=T w$. From (34), with $x=w$ and $y=x_{n+1}$, we have

$$
G\left(z, x_{n}, x_{n-1}\right)=G\left(T w, T x_{n+1}, T^{2} x_{n+1}\right) \geq \alpha G\left(w, T w, T^{2} w\right) .
$$

Taking limit as $n \rightarrow \infty$ in the inequality above, we have $G\left(w, T w, T^{2} w\right)=0$. That is, $w=$ $T w=T^{2} w$. To prove the uniqueness, suppose that $u \neq v$ such that $T v=v$ and $T u=u$. 


\section{Acknowledgements}

The authors thank to anonymous referees for their remarkable comments, suggestions and ideas that helped to improve this paper.

Received: 17 July 2013 Accepted: 16 September 2013 Published: 07 Nov 2013

\section{References}

1. Mustafa, Z, Sims, B: A new approach to generalized metric spaces. J. Nonlinear Convex Anal. 7, 289-297 (2006)

2. Mustafa, Z, Sims, B: Fixed point theorems for contractive mappings in complete G-metric spaces. Fixed Point Theory Appl. 2009, Article ID 917175 (2009)

3. Mustafa, Z, Obiedat, H, Awawdeh, F: Some fixed point theorem for mapping on complete G-metric spaces. Fixed Point Theory Appl. 2008, Article ID 189870 (2008)

4. Mustafa, Z: A new structure for generalized metric spaces with applications to fixed point theory. PhD thesis, The University of Newcastle, Australia (2005)

5. Mustafa, Z, Khandaqji, M, Shatanawi, W: Fixed point results on complete G-metric spaces. Studia Sci. Math. Hung. 48, 304-319 (2011)

6. Mustafa, Z, Aydi, H, Karapınar, E: Mixed g-monotone property and quadruple fixed point theorems in partially ordered metric space. Fixed Point Theory Appl. 2012, 71 (2012)

7. Rao, KPR, Bhanu Lakshmi, K, Mustafa, Z: Fixed and related fixed point theorems for three maps in G-metric space. J. Adv. Stud. Topol. 3(4), 12-19 (2012)

8. Mustafa, Z: Common fixed points of weakly compatible mappings in G-metric spaces. Appl. Math. Sci. 6(92), 4589-4600 (2012)

9. Shatanawi, W, Mustafa, Z: On coupled random fixed point results in partially ordered metric spaces. Mat. Vesn. 64 139-146 (2012)

10. Mustafa, Z: Some new common fixed point theorems under strict contractive conditions in G-metric spaces. J. Appl. Math. 2012, Article ID 248937 (2012)

11. Mustafa, Z: Mixed $g$-monotone property and quadruple fixed point theorems in partially ordered G-metric spaces using $(\phi-\psi)$ contractions. Fixed Point Theory Appl. 2012, 199 (2012)

12. Mustafa, Z, Shatanawi, W, Bataineh, M: Existence of fixed point results in G-metric spaces. Int. J. Math. Math. Sci. 2009, Article ID 283028 (2009)

13. Aydi, H, Postolache, $M$, Shatanawi, W: Coupled fixed point results for $(\psi, \phi)$-weakly contractive mappings in ordered G-metric spaces. Comput. Math. Appl. 63(1), 298-309 (2012)

14. Aydi, H, Damjanović, B, Samet, B, Shatanawi, W: Coupled fixed point theorems for nonlinear contractions in partially ordered G-metric spaces. Math. Comput. Model. 54, 2443-2450 (2011)

15. Luong, NV, Thuan, NX: Coupled fixed point theorems in partially ordered G-metric spaces. Math. Comput. Model. 55, 1601-1609 (2012)

16. Aydi, H, Karapınar, E, Shatanawi, W: Tripled fixed point results in generalized metric spaces. J. Appl. Math. 2012, Article ID 314279 (2012)

17. Aydi, H, Karapınar, E, Mustafa, Z: On common fixed points in G-metric spaces using (E.A) property. Comput. Math. Appl. 64(6), 1944-1956 (2012)

18. Tahat, N, Aydi, H, Karapınar, E, Shatanawi, W: Common fixed points for single-valued and multi-valued maps satisfying a generalized contraction in G-metric spaces. Fixed Point Theory Appl. 2012, 48 (2012)

19. Aydi, H, Karapınar, E, Shatanawi, W: Tripled common fixed point results for generalized contractions in ordered generalized metric spaces. Fixed Point Theory Appl. 2012, 101 (2012)

20. Agarwal, R, Karapınar, E: Remarks on some coupled fixed point theorems in G-metric spaces. Fixed Point Theory Appl. 2013, 2 (2013)

21. Karapınar, E, Kaymakcalan, B, Tas, K: On coupled fixed point theorems on partially ordered G-metric spaces. J. Inequal. Appl. 2012, 200 (2012)

22. Ding, HS, Karapınar, E: A note on some coupled fixed point theorems on G-metric space. J. Inequal. Appl. 2012, 170 (2012)

23. Gül, U, Karapınar, E: On almost contraction in partially ordered metric spaces viz implicit relation. J. Inequal. Appl. $2012,217(2012)$

24. Samet, B, Vetro, C, Vetro, F: Remarks on G-metric spaces. Int. J. Anal. 2013, Article ID 917158 (2013)

25. Jleli, M, Samet, B: Remarks on G-metric spaces and fixed point theorems. Fixed Point Theory Appl. 2012, 210 (2012)

26. Saadati, R, Vaezpour, $S M$, Vetro, P, Rhoades, BE: Fixed point theorems in generalized partially ordered G-metric spaces. Math. Comput. Model. 52, 797-801 (2010)

27. Agarwal, R, Karapınar, E: Further fixed point results on G-metric spaces. Fixed Point Theory Appl. 2013, 154 (2013)

28. Mustafa, Z, Aydi, H, Karapınar, E: Generalized Meir Keeler type contractions on G-metric spaces. Appl. Math. Comput. 219(21), 10441-10447 (2013)

29. Alghamdi, MA, Karapınar, E: G- $\beta-\psi$ contractive type mappings and related fixed point theorems. J. Inequal. Appl. 2013, 70 (2013)

30. Bilgili, N, Karapınar, E: Cyclic contractions via auxiliary functions on G-metric spaces. Fixed Point Theory Appl. 2013, 49 (2013)

31. Ding, H-S, Karapınar, E: Meir Keeler type contractions in partially ordered G-metric space. Fixed Point Theory Appl. 2013, 35 (2013)

32. Roldan, A, Karapınar, E: Some multidimensional fixed point theorems on partially preordered $G^{*}$-metric spaces under $(\psi, \varphi)$-contractivity conditions. Fixed Point Theory Appl. 2013, 158 (2013)

33. Alghamdi, MA, Karapınar, E: G- $\beta$ - $\psi$ contractive type mappings in G-metric spaces. Fixed Point Theory Appl. 2013 123 (2013)

34. Banach, S: Sur les opérations dans les ensembles abstraits et leur application aux équations intégrales. Fundam. Math. 3, 133-181 (1922) 
10.1186/1029-242X-2013-454

Cite this article as: Asadi et al.: A new approach to $G$-metric and related fixed point theorems. Journal of Inequalities and Applications 2013, 2013:454

Submit your manuscript to a SpringerOpen ${ }^{\circ}$ journal and benefit from:

- Convenient online submission

- Rigorous peer review

- Immediate publication on acceptance

Open access: articles freely available online

- High visibility within the field

- Retaining the copyright to your article

Submit your next manuscript at $\boldsymbol{s p r i n g e r o p e n . c o m ~}$ 